Provided for non-commercial research and education use. Not for reproduction, distribution or commercial use.

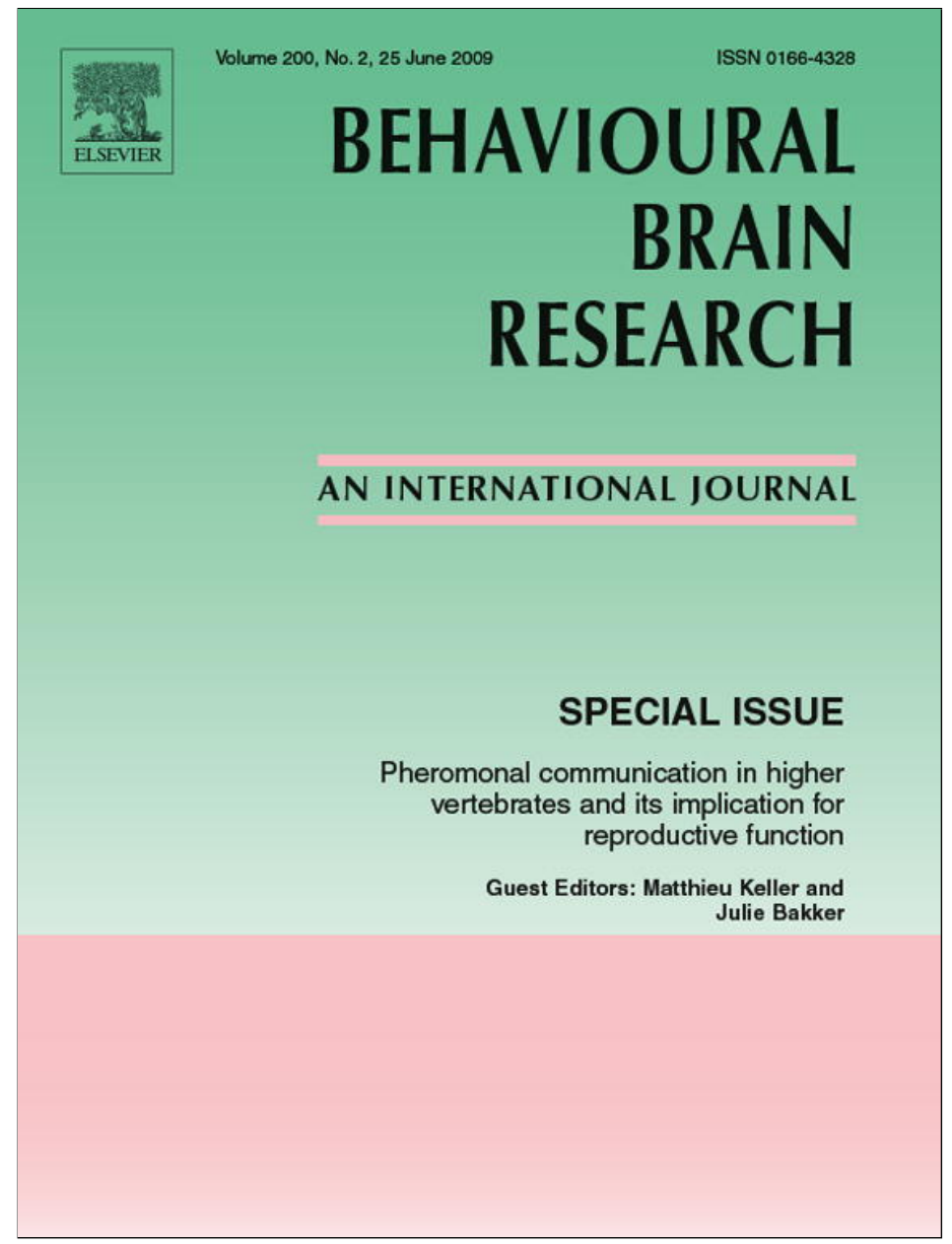

This article appeared in a journal published by Elsevier. The attached copy is furnished to the author for internal non-commercial research and education use, including for instruction at the authors institution and sharing with colleagues.

Other uses, including reproduction and distribution, or selling or licensing copies, or posting to personal, institutional or third party websites are prohibited.

In most cases authors are permitted to post their version of the article (e.g. in Word or Tex form) to their personal website or institutional repository. Authors requiring further information regarding Elsevier's archiving and manuscript policies are encouraged to visit:

http://www.elsevier.com/copyright 
Research report

\title{
The main and the accessory olfactory systems interact in the control of mate recognition and sexual behavior
}

\author{
Matthieu Keller ${ }^{\mathrm{a}, *}$, Michael J. Baum ${ }^{\mathrm{b}}$, Olivier Brock ${ }^{\mathrm{c}}$, Peter A. Brennan ${ }^{\mathrm{d}}$, Julie Bakker ${ }^{\mathrm{c}}$ \\ a Behavioral \& Reproductive Physiology, UMR 6175 INRA/CNRS/University of Tours, Nouzilly, France \\ ${ }^{\mathrm{b}}$ Department of Biology, Boston University, USA \\ c Behavioral Neuroendocrinology, Center for Cellular E' Molecular Neurobiology, University of Liège, Belgium \\ d Department of Physiology \& Pharmacology, University of Bristol, United Kingdom
}

\section{A R T I C L E I N F O}

\section{Article history:}

Received 26 December 2008

Received in revised form 13 January 2009

Accepted 14 January 2009

Available online 23 January 2009

\section{Keywords:}

Pheromones

Vomeronasal organ

Main olfactory epithelium

Olfactory bulb

\begin{abstract}
A B S T R A C T
In the field of sensory perception, one noticeable fact regarding olfactory perception is the existence of several olfactory subsystems involved in the detection and processing of olfactory information. Indeed, the vomeronasal or accessory olfactory system is usually conceived as being involved in the processing of pheromones as it is closely connected to the hypothalamus, thereby controlling reproductive function. By contrast, the main olfactory system is considered as a general analyzer of volatile chemosignals, used in the context of social communication, for the identification of the status of conspecifics. The respective roles played by the main and the accessory olfactory systems in the control of mate recognition and sexual behavior are at present still controversial. We summarize in this review recent results showing that both the main and accessory olfactory systems are able to process partially overlapping sets of sexual chemosignals and that both systems support complimentary aspects in mate recognition and in the control of sexual behavior.
\end{abstract}

(C) 2009 Elsevier B.V. All rights reserved.
Among the various communication strategies that have evolved in mammalian species, smell is surely the most widespread and the most conserved [106]. In the field of chemosensory communication, Karlson and Lüscher [43] introduced the concept of "pheromones" as chemosignals that provide information to conspecifics about sex or endocrine status or which stimulate hard-wired species-specific social behaviors. Traditionally, pheromones have been classified as either "releaser pheromones" which trigger an immediate response or as "primer pheromones" inducing long-term changes in behavior or physiology. More recently, a new terminology has been introduced, including "signaler pheromones", which induce behavioral or physiological changes depending on the identity of the individuals emitting or sending the pheromonal signal. However, it is difficult to classify specific pheromonal compounds regarding their neurobiological processing and/or their behavioral action and consequently there has been some controversy about the use and definition of the term "pheromone". For example, a pheromonal compound such as brevicomin can act either as a releaser pheromone, eliciting aggressive responses in conspecific males, or as a primer pheromone, inducing estrus in female mice [81].

\footnotetext{
* Corresponding author at: Laboratoire de Physiologie de la Reproduction \& des Comportements, UMR 6175 INRA/CNRS/Université de Tours, 37380 Nouzilly, France. Tel.: +33 247427 275; fax: +33247427 743 .

E-mail address: mkeller@tours.inra.fr (M. Keller).
}

Despite these controversies, it is clear that olfactory/pheromonal signals profoundly influence neuroendocrine functioning and regulate a wide variety of social behaviors including sexual interactions, parent-offspring relations and interindividual aggression. In the field of sexual functioning, olfactory cues and pheromones are probably the most powerful signals mediating the influence of social environment on reproductive function in many species. For example, pheromones have been shown to influence nearly all stages of reproductive life including the modulation of sexual maturation and puberty [110], the suppression of estrous cyclicity [115], the mediation of mate recognition and sexual interactions $[3,47]$, the disruption of pregnancy $[13,14,18]$ or the initiation of maternal behavior at parturition $[58,59]$.

Finally, one noticeable fact in the physiology of olfaction is the existence of at least two distinct but complementary systems for the detection of chemosensory molecules, namely the main and the accessory olfactory systems $[12,15,75,102]$ (see [11] for the newly chemosensory system identified in the Grueneberg ganglion) in most mammalian species. These olfactory systems have evolved so that they differ in their peripheral anatomy, their central projections and also in their function. However, both systems may also function synergistically in sustaining some pheromone-dependent behaviors $[7,48,90]$. Therefore, a central problem in olfaction is to elucidate the relative roles played by both systems in detecting olfactory information and in regulating chemosensory-dependent behaviors. In this review, we will focus on the relative roles of the 
main versus accessory olfactory systems in the processing of sexual olfactory/pheromonal chemosignals and their involvement in the control of sexual interactions, including mate recognition, as well as how these olfactory systems are regulated by gonadal hormones.

\section{Functional organization of both the accessory and main olfactory systems}

\subsection{The accessory olfactory system}

The accessory olfactory system, through its close connections with the reproductive hypothalamus, is usually conceived to be involved in the detection of odors that influence reproductive behaviors and as a consequence triggers neuroendocrine changes leading to puberty acceleration, estrous induction, and pregnancy block, as well as the testosterone increases in males when exposed to urine from estrous females [51,52,91]. The sensory neurons of the accessory olfactory system are found in the vomeronasal organ (VNO), a blind-ended tube located at the basis of the nasal septum which opens via a small duct into the nasal cavity or into the mouth depending on the species. The VNO detects pheromones which gain access to the VNO by a vascular pumping mechanism [78]. Indeed, many mammalian species engage in intense physical investigation of scent sources, thus exposing VNO sensory neurons to chemosignals which are pumped into the lumen of the VNO when the animal is attending to the stimulus [66,76]. Pheromonal ligands then interact with receptors on the membrane of VNO sensory neurons. These vomeronasal receptors have been identified and classified in two distinct families: the vomeronasal type 1 (V1Rs) and type 2 receptors (V2Rs). Both types of receptors share little sequence homology and are thought to have an ancient evolutionary origin $[51,52]$. In addition, both types of receptors are expressed in different regions of the VNO: V1Rs are expressed in the apical part of the VNO, near the lumen, while V2Rs are expressed in the more basal region $[14,38]$. This regionalization is conserved at the level of the first olfactory relay, the AOB, where V1Rs neurons send projections exclusively to the rostral part of the AOB while the V2Rs neurons project to the caudal part of the AOB. It has been shown that these subdivisions of the VNO and AOB sustain functional differences as they respond differentially to pheromonal stimuli in mice $[16,37]$. After the first olfactory relay, mitral cells of the AOB project in turn to the medial nucleus of the amygdala, where information processed in the two parts (rostral vs caudal) of the vomeronasal pathway converge when their projections overlap in this structure [111]. Olfactory information is then dispatched to several hypothalamic and limbic regions involved in the regulation of reproductive behavior such as the bed nucleus of the stria terminalis (BnST), the medial preoptic area (MPOA) and the ventromedial hypothalamus [93] and thus bypass higher cognitive cortical centers.

\subsection{The main olfactory system}

The vomeronasal system has traditionally been the main focus for pheromonal research, while the main olfactory system has been considered as a general analyzer that detects and differentiates among complex chemosignals that are present in the physical and social environment of individuals [31]. However, some mammalian pheromones have long been known to be detected by the main olfactory system (MOS; [12]. In the MOS, chemosignals are detected by olfactory sensory neurons located in the main olfactory epithelium (MOE). These sensory neurons represent the start point of the central treatment of olfactory information as they project their axons through the cribiform plate to converge at the first relay of the central olfactory system in the brain: the glomeruli of the main olfactory bulb (MOB) [19]. It should be noticed that individual sen- sory neurons in the MOE project a single axon to a single glomerulus in the MOB, therefore, the glomerular layer of the MOB forms a map of olfactory axons terminals $[19,120]$. These projections of the MOE sensory neurons are precisely organized so that MOE sensory neurons expressing a given odorant receptor send their axons to a few converging glomeruli with a fixed topographical localization. The mitral and tufted cells abutting these MOB glomeruli then transmit olfactory signals to various forebrain and cortical targets including the piriform cortex, the entorhinal cortex or the anteriorcortical nucleus of the amygdala [93].

\subsection{Convergence between main and accessory olfactory pathways}

While main and accessory olfactory systems exhibit segregated pathways at the level of the first olfactory relays, the two systems converge downstream at several levels, including the cortical-medial amygdala $[33,53,54,75,77,93,107]$. Indeed, electrical stimulations of both the MOB and vomeronasal organ induce electrophysiological activation of this structure [61,77]. More interestingly, single neurons have been shown to respond to these stimulations, suggesting that both systems can interact in the processing of olfactory/pheromonal signals at the single cell level in the amygdala and interact downstream towards the BnST or MPOA which are of great importance in the regulation of sexual behavior. In addition, it has been recently suggested that the AOB receives backward connections from several forebrain sites including the bed nucleus of the accessory olfactory tract, the rostral portion of the medial amygdala (MeA), and the posteromedial cortical nucleus of the amygdala (PMCo). When exposed to male urinary volatiles, these connections show specific activation, suggesting that main olfactory-MeA-AOB signaling may motivate approach behavior to opposite-sex pheromonal signals that ensure successful reproduction [71].

Another site of cellular convergence of both olfactory systems appears to be the gonadotropin-releasing hormone ( $\mathrm{GnRH})$ neurons. Indeed, it is widely accepted that the effects of pheromones on neuroendocrine status are mediated by GnRH neurons which are found scattered in the anterior hypothalamus $[77,80,113,114]$. Several sets of experiments have repeatedly demonstrated that the vomeronasal system sends projections to the GnRH neurons, and that pheromonal signals processed through the vomeronasal system can activate these neurons [80,113,114]. However, while recent experiments confirmed that GnRH neurons receive signals from subsets of neurons located in the vomeronasal system, they also, and more surprisingly, demonstrated that $\mathrm{GnRH}$ neurons receive connections from the main olfactory system $[10,119]$ suggesting that GnRH neurons can receive information about odorants processed by both olfactory systems. Interestingly, GnRH neurons have bidirectional contacts with both main and accessory olfactory systems-relay areas, implying that they can also modulate the processing and transmission in both olfactory systems. Finally, $\mathrm{GnRH}$ neurons contact brain areas associated with sexual behavior whose connections exhibit sexual dimorphism. All these results suggest that both olfactory systems converge on and can impact GnRH neurons and in turn influence sexual behavior $[10,119]$.

\section{Functional roles of both the main and the accessory olfactory systems in pheromonal processing}

The vomeronasal system is known to be involved in several pheromone-induced physiological responses in mice, including puberty acceleration, estrus induction, and pregnancy block-confirming the traditional view of the vomeronasal pathway. In the case of pregnancy block (Bruce effect) the pregnancy of recently mated females is disrupted if these females are exposed to the urine of an unfamiliar male $[12,15,18]$. This effect is based 
on females' learning of the mating male's olfactory signature during the immediate post-copulatory period. Once this learning is established, the urine of the mating male will not induce this pregnancy failure, contrary to the urinary odors of unfamiliar males. Although the nature of the signal supporting the Bruce effect is still unclear (see [13] this issue for a complete discussion of this point), the MHC class-1 peptides [57] have been shown to convey, through their action on the V2R-expressing receptor neurons in the basal $\mathrm{VNO}$, some information about the individuality of the mating male. Lesioning the VNO itself or any other level of the vomeronasal pathway has been shown to consistently disrupt the pregnancy block effect $[8,64]$. Lesions to the VNO have also been shown to disrupt other pheromonally induced behaviors, such as the acceleration of puberty, measured through the occurrence of the first estrous cycle, which is observed in pre-pubertal female mice that are exposed to male olfactory cues (Vandenbergh effect; [65], or the suppression of the estrous cycle that occurs after housing adult females together (Whitten effect) [27,115].

By contrast, the MOS is traditionally thought to be involved in the processing of odors related to social attraction and complex social recognition, thus allowing animals to distinguish sex, social or reproductive status of conspecifics. Indeed, urine, like most other social olfactory stimuli, consists of a large number of distinct chemical compounds that vary according to the sex, strain, social and physiological status of the emitter $[1,42]$. For example, the volatile urinary compound (methylthio) methanethiol (MTMT) has been shown to activate a subset of mitral cells in the MOB, and when added to urine, enhances urine attractiveness to female mice [62]. In this context, the anatomical segregation of the two systems and the extensive functional differences between them have given rise to the traditional view that the MOE detects volatile odorants in the environment while the VNO detects non-volatile pheromones $[15,19]$. In support of this functional dichotomy, Luo et al. have demonstrated using electrophysiological recordings of mitral cells in the AOB in behaving animals that these cells are only activated when mice make direct physical contact with the odorant source (either the face or anogential regions of an anaesthetised stimulus female [66]).

The functional dichotomy between both main and accessory olfactory systems is not so clear-cut and it is now necessary to revise this segregation. This revision is based on recent experimental facts showing that both the VNO and the MOE have the ability to detect some overlapping sets of chemosensory cues. Some of the experiments supporting this view are listed below. First, the view that the VNO is only involved in the detection of non-volatile odors has recently been challenged by using both electrophysiological and imaging methods. With these new approaches, several groups have demonstrated, using in vitro preparations, that VNO neurons can express very sensitive and specific responses to urinary or bodily volatile compounds, such as farnesenes or brevicomine [23,56]. However, the general view is that these volatile ligands need to be transported into the VNO by transport proteins belonging to the lipocalin family; in vivo, such molecules gain access to the VNO after direct contact with the stimulus source. Among these proteins that act as carrier for volatile ligands, some, such as major urinary proteins (MUPs) $[15,40]$ or aphrodisin [17] have been now clearly characterized. It should be noticed that these carrier proteins might also serve by themselves as cues for individual recognition, especially because they exhibit a high degree of polymorphism [40] and are able to stimulate egr- 1 expression in specific regions of the accessory olfactory bulb [16].

Whether the accessory olfactory system can be directly stimulated by volatile pheromones (i.e. without direct physical contact with the olfactory source) remains controversial but some experiments reported the activation of the AOB by volatile compounds delivered in the airstream $[70,118]$. In addition, other indirect behavioral evidence for a role of the VNO in the detection of volatile molecules comes from the study by Trinh and Storm [109], who used transgenic mice with a nonfunctional cAMP signaling pathway in the olfactory epithelium due to a mutation in type 3 adenylyl cyclase (AC3). Such AC3 KO mice were able to detect several volatile odorants, including putative pheromones, presumably via the VNO. However, more recently it was shown that mice defective in the olfactory cAMP signaling pathway can detect some volatile odorants through their olfactory epithelium using alternative transduction pathways [63].

It has also been known for a long time that some pheromones can be detected by the main olfactory system. For example, the volatile steroid androstenone in boar saliva induces lordosis in receptive sows $[25,26]$. Indeed, this volatile chemosignal continues to induce lordosis in female sows even if their VNO is blocked, suggesting that it is detected and processed by the MOE. In sheep, the male effect, characterized by the occurrence, during the anestrous period, of a preovulatory LH surge and ovulation in ewes, is due to exposure to ram odors and involves the main olfactory system [21,24,32]. Indeed, lesioning the vomeronasal pathway does not affect the ewe's neuroendocrine LH response to the ram. In mice, MTMT in male mouse urine is also detected by the MOB and is a potent attractant for female mice [62]. With regard to mother-young relationships, the rabbit mammary pheromone 2-methylbut-2enal present in the milk of the mother induces nipple-searching behavior in pups [94]; removal of the VNO has no effect on the nipple-search behavior while ablation of the MOE abolishes it completely [39]. Finally, with regard to humans, who do not have a functional VNO and in whom an AOB has never been identified, it has been shown that exposing women with normal menstrual cycles to axillary extracts from women in their follicular phase shortens the length of the recipient's menstrual cycle [104]. Furthermore, Shinohara et al. [100] reported that women exposed to female axillary secretions showed changes in LH pulses. Finally, Preti et al. [88] showed that male axillary extracts affected pulsatile secretion of LH and mood in women recipients. These studies thus showed that axillary secretions contain one or more compounds that may act as a pheromone in humans.

Additionally, some pheromonal signals may also be processed in parallel by the two olfactory systems. Calcium imaging studies with in vitro preparation of nasal tissue have shown that some sensory neurons respond to MHC peptides in both the VNO and the MOE [103]. Indeed, it has been demonstrated that non-volatile olfactory cues can also gain access to the MOE after direct physical contact [103]. The thresholds of sensory neurons responses to MHC peptides differ in both VNO and MOE, with values in the nanomolar range for vomeronasal sensory neurons [57] and near $10^{-10} \mathrm{M}$ in the MOE [103]. The mechanisms underlying the detection for the same chemosignals by sensory neurons in the VNO and MOE depends on distinct sets of transduction mechanisms. For example, local field potentials to MHC peptides are inhibited by the drug 2-aminoethoxydiphenylborate (or 2-APB) in the VNO, but not in the MOE [57,103]. In addition, MOE responses to MHC peptides are inhibited by adenylcyclase antagonists and critically depend on a functional CNGA4 gene, which encodes a principal subunit of a cyclic AMP-sensitive CNG channel expressed in MOE but not in the VNO, thus showing that MHC peptides ligands are transduced in the MOE by cells employing a cAMP-signaling pathway and the olfactory CNG channel. Similar results have been obtained with the odorant 2-heptanone: its detection appears to be dependent on the Trp2 gene in the VNO, while in the MOE, detection of 2-heptanone depends on the CNGA2 [60,63]. At the behavioral level, this processing of the same olfactory signals is not just a redundancy. Indeed, specific activation of each system can lead to distinct behavioral outcomes. Thus, in the vomeronasal system, MHC-class I peptides signals has been shown to sustain information about individuality 
in the context of the Bruce effect [57] while processing of MHCclass I peptides in the MOE support social preferences [103]. This demonstrates that MHC processing via the MOE does not replace VNO sensory inputs.

\section{Both main and accessory olfactory systems interact in the control of mate recognition and sexual behavior}

\subsection{Olfactory control of mate recognition}

As mentioned previously, it is generally believed that recognition/discrimination as well as attraction to the opposite sex involves the main olfactory pathway. Indeed, this has been demonstrated to be the case in several species including rodents, ferrets, pig or monkeys. By contrast, the accessory olfactory pathway is thought to control sexual behavior due to its connections with the hypothalamus. However no general consensus has been yet established and a recent series of experiments based on specific lesions of the main versus accessory olfactory pathways have started to establish more precisely the relative roles of both systems in the control of mate recognition.

The general view that attraction/recognition toward the opposite sex involves the main olfactory system is based on the fact that sexual discrimination is usually achieved by animals of both sexes on the sole basis of volatile olfactory cues. These results have been consistently obtained using various behavioral paradigms including habituation/dishabituation tests [6,86], Y-maze preference tests $[44,45,83]$ or studies using olfactory go-no-go conditioning procedures [101,112]. In this context, recent olfactometer experiments performed by our group have confirmed and further explored sexual discrimination abilities of female mice on the sole basis of volatile odors. Briefly, the general principle of olfactometry is as follows: the olfactometer presents an odor when the mouse breaks a photobeam in the odor sampling tube with its snout (Fig. 1A1; see [112] for further experimental details). When the photobeam is broken, a stream of purified air displaces the volatile odor headspace in the odor vials, sending this odor through a mixing manifold to pass by the nose of the animal as it licks from a reward spout (Fig. 1A2). In this go/no-go discrimination paradigm, mice were rewarded with Pediasure ${ }^{\circledR}$ when they responded correctly by licking to the presentation of the S+ (hit) odor (Fig. 1A3). If the animal did not lick for presentation of the S+ odor (miss) or did lick for presentations of the $\mathrm{S}$ - odor (false alarm), it was given a negative score. Alternatively, in cases when the animal did not lick for presentations of the $S$ - odor (correct reject), the animal received a positive score (Fig. 1A4). After the completion of a trial, the next trial started after an inter-trail interval of $5 \mathrm{~s}$ (Fig. 1A5). Olfactory discrimination was assessed during $8 \mathrm{~S}+/ \mathrm{S}-$ blocks of 20 trials followed by a control block $(\mathrm{S}-/ \mathrm{S}-)$ and a final block $\mathrm{S}+/ \mathrm{S}-$ block. As illustrated in Fig. 1B, experimental C57Bl6 female mice $(n=7)$ readily discriminated volatile olfactory cues emanating from male mouse urine versus estrous female urine. Very similar results were obtained when the same kind of discrimination task was administered to mice using low molecular weight urinary fractions which contain only volatile odors (LMW; see [46] for details regarding biochemical separation of low molecular versus high molecular urine fractions; HMW). By contrast, mice failed to discriminate the odors when the task was performed using non-volatile urinary fractions (Fig. 1C). Reloading HMW with LMW fractions restored discrimination between male versus estrous female urinary cues. Additionally, we also demonstrated that the volatile male mouse pheromone, MTMT, can be discriminated at a concentration as low as $10 \mathrm{nM}$ when added to a solution of gonadectomized male urine diluted in water (Fig. 1D). In support of this behavioral result, this molecule has been recently shown to induce attraction of female mice at a concentration of $20 \mathrm{nM}$, and electrophysiological work has demonstrated that MTMT induced clear responses in MOB mitral cells of female mice, indicating that the main olfactory system mediates the attraction of females to this pheromone [62]. Finally, mice were also able to discriminate between volatile urinary cues derived from congenic mouse urine ( $\mathrm{C} 57 \mathrm{BL} / 10 \mathrm{~J}$ mice $(\mathrm{bb}$ at $\mathrm{H}-2)$ and C57BL/10J-H-2k (kk at H-2); Fig. 1E). This result confirmed previous experiments performed by various groups who demonstrated that mice lacking a vomeronasal organ can discriminate between MHC odortypes [117] and MHC-class I peptides [50]. This whole set of results further suggests that volatile olfactory cues are strictly processed by the main olfactory system, at least when physical contact with the odor source is prevented.

The involvement of the main olfactory system in mate recognition has been confirmed by lesion studies of main olfactory function using intranasal application of zinc sulphate $[44,45]$. In both sexes, lesioning the MOS completely suppressed the preference for opposite-sex olfactory cues observed in both Y-maze and habituation/dishabituation experiments. This effect of zinc sulphate lesioning was not only obtained when the animals were provided with volatile olfactory stimuli, but also when direct contact with olfactory cues was allowed, thus providing both volatile and non-volatile olfactory cues. This latter result suggests that, zinc sulphate-treated animals do not detect the volatile odors released from odor sources and subsequently are not attracted to investigate them further. This is in line with previous observations in OMP-ntr mice, where targeted destruction of the MOE made it impossible for female mice to locate male urine spots placed in their home cage [67].

Complimentary to the results detailed previously, surgical lesions of the VNO clearly showed that this treatment is not effective in disrupting mate recognition in both male and female mice $[44,45,82,83]$. Indeed, VNO-lesions did not impair the discrimination of body or urinary volatile odorants in a habituation/dishabituation test as well as the preference for opposite-sex-derived volatile odors measured in Y-maze choicetests. The lack of involvement of the vomeronasal pathway to support mate recognition has also been demonstrated in female ferrets, where lesioning the VNO did not affect the preference for volatile body odorants emitted from males [116]. By contrast, blocking the nares of the animals disrupted mate recognition in both male and female ferrets [49]. In addition, VNO duct occlusion failed to disrupt female attraction toward the boar pheromone, androstenone, [26]. Interestingly, these results demonstrating the lack of a role for the VNO in mate recognition, have been broadly confirmed by performing lesions downstream in the accessory olfactory pathway at the level of the AOB $[41,72]$. The fact that mate recognition is not disrupted when the $A O B$ is lesioned also confirms that previous results obtained by surgical removal of the VNO were not the consequence of an occlusion of the nasal cavity by blood clots, as was recently suggested by Kimchi et al. [55].

Despite this convergent body of results, a role for the VNO in mate recognition has been recently claimed by studies using transient receptor potential cation 2 channel knock-out male mice $[60,105]$. Indeed, deletion of $\operatorname{Trp} 2$ results in a dramatic reduction of various electrophysiological responses in VNO sensory neurons after exposure to urinary odorants. In addition, at the behavioral level, Trp2-KO male mice mounted male and female subjects indiscriminately $[60,105]$, leading to the conclusion that the VNO is required for sex discrimination. However neither study measured olfactory sex discrimination directly. It remains questionable whether Trp2-KO males can discriminate between the sexes on the basis of olfactory cues. These results can, however, be reconciled with previous findings because in a recent study performed by Kelliher et al. [50], Trp2-KO mice showed electrophysiological responses after being stimulated with MHC-class I peptides; in addition these mice showed a pregnancy block effect when exposed 


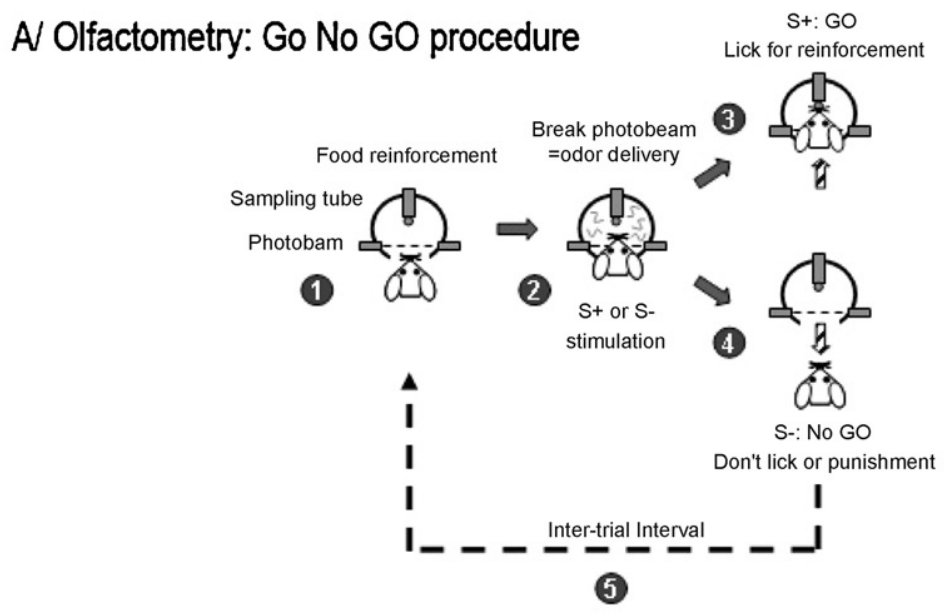

B/ Male Urine (10-2, S+) vs estrus female (10-2, S-)
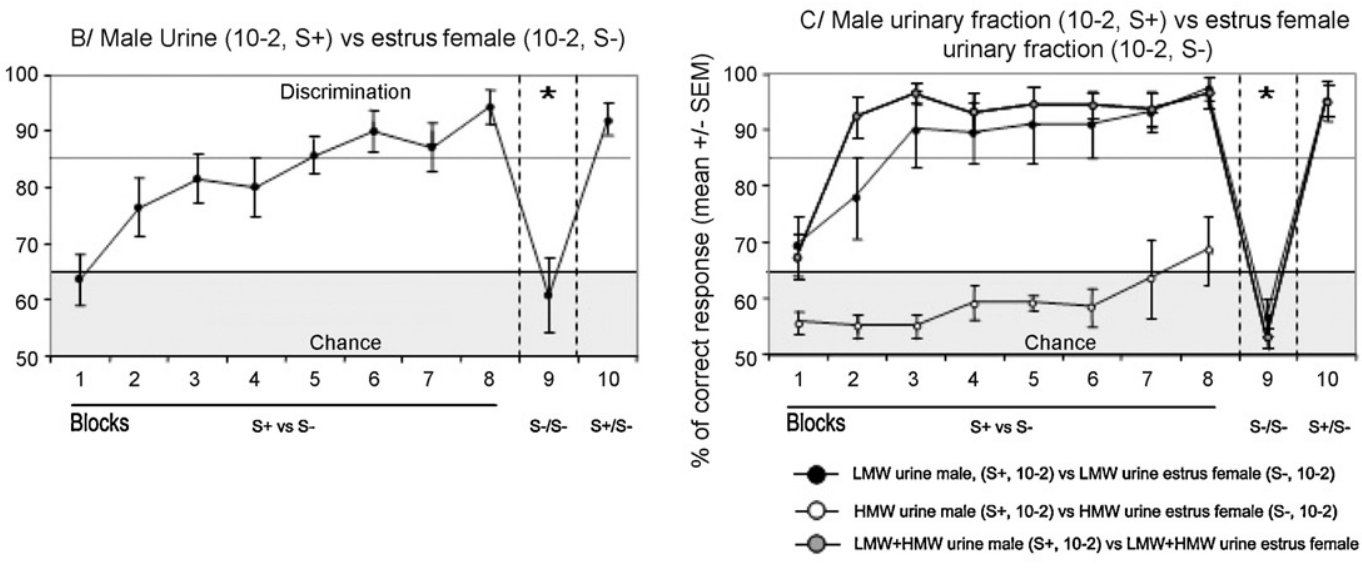

D/ MTMT (10.10-9) in gdx male urine (10-2) (S+) vs gdx male urine (S-, 10-2)
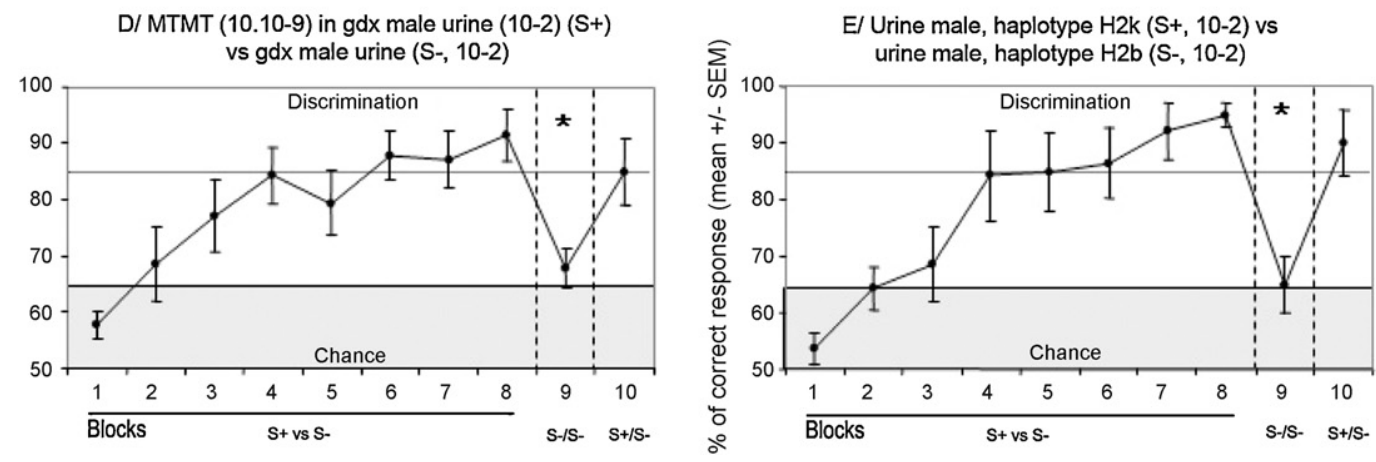

Fig. 1. (A) procedure for assessing odor discrimination capacity using a liquid olfactometer. Briefly, the olfactometer presents an odor when the mouse breaks a photobeam with its snout. When the photobeam is broken, a stream of purified air displaces the odor headspace in the odor vials, sending this odor through a mixing manifold to pass by the nose of the animal as it licks from a reward spout. In this go, no-go discrimination paradigm, mice were rewarded with approximately $3 \mu l$ of Pediasure when they responded correctly by licking to the presentation of the $\mathrm{S}+($ hit) odor. If the animal did not lick for presentation of the $\mathrm{S}+$ odor (miss) or did lick for presentations of the Sodor (false alarm), it was given a negative score. Alternatively, in cases when the animal did not lick for presentations of the $\mathrm{S}-$ odor (correct reject), the animal received a positive score. Results are expressed as percentage of correct responses by blocks of 20 trials. For each discrimination task, female mice ( $n=7$ ) were submitted to eight discrimination blocks $(\mathrm{S}+/ \mathrm{S}-)$, followed by a control block $\left(\mathrm{S}-/ \mathrm{S}_{-}\right)$to discard any potential contamination allowing to achieve the discrimination task through non specific olfactory cues; during this control block performance was expected to be under the chance threshold (set-up at 65\%); a final discrimination was performed to test for recovery of normal performance. (B-E) discrimination task involving (B) male vs estrous female urine (dilution of urine $10^{-2}$, see [112] for experimental details), (C) low molecular urinary fraction (black circles), high molecular urinary fraction (white circles) and high molecular fraction reloaded with low molecular fraction; all fractions derived from male vs estrous female urine (see [46] for separation of urinary fractions), (D) (methylthio)methanethiol diluted in gonadectomized male urine vs gonadectomized male urine and (E) urine of congenic mice. Discrimination tasks were performed in the order described previously. Results clearly demonstrated that volatile urinary cues are sufficient for mate recognition in female mice.

to the odor of a strange male. These results indicate that ablation of Trp2 cannot be considered as being totally equivalent to a complete elimination of VNO function. Instead, it seems likely that some VNO function, presumably involving the V2-R expressing receptor neurons, is retained in Trp2 KO mice. Finally, it must be mentioned that when direct access to the odorant source is provided to VNO lesioned animals in Y-maze odor preference tests, olfactory investigation and preference is clearly disrupted, suggesting that the VNO can contribute to subject's motivation to approach and investigate potential mates. However, this appears to be only on the basis on non-volatile olfactory cues detected through direct physical contact with the odorant source [46]. 


\subsection{Olfactory control of sexual behavior}

Which olfactory system mediates sexual behavior in mice has also been a matter of debate. In the male, the involvement of VNO in copulatory behavior seems to vary according to the species. In male mice, lesioning the VNO is without any impact on male sexual behavior [82] and Trp2-KO male mice also show normal levels of copulation [105]. These results point to a possible role for the main olfactory system in the expression of male sexual behavior [45]. However, genetic ablation of a subset of V1Rs has significant effects on sexual behavior in males [23]. In other species such as hamsters or prosimian primates (Microcebus murinus), surgical ablation of the VNO seemed to have more dramatic effects on the display of sexual behaviors $[2,87]$. However, in mice, male sexual behavior has been shown to be more generally dependent on a functioning MOE. Indeed, if initial studies by Edwards and Burge [28] suggested that the MOE was not involved in controlling male sexual behavior, this result has recently been challenged by various studies, using either chemical lesions of the MOE with dichlobenil [119] or zinc sulphate [45] or using genetically engineered mice lacking CNGA2, a channel that is only expressed in MOE sensory neurons [69]. All studies showed a dramatic disruption of sexual behavior after destruction/inactivation of the MOE, which is in sharp contrast with the results of Edwards and Burge [28]. Sexual experience may account for these discrepancies as at the behavioral level, sexual experience is a factor allowing the integration of chemosignals originating from both main and accessory olfactory systems.

Indeed, the integration of the ability to mate is, in male hamsters, dependent on sexual experience and integration of vomeronasal cues with main olfactory cues $[74,84]$. In sexually naïve males, severe deficits in mating behavior can be observed following removal of the VNO, demonstrating that vomeronasal inputs are necessary to achieve copulation in these animals. By contrast, either main or vomeronasal inputs are sufficient for mating to occur in sexually experienced males, and only lesioning of both systems impairs copulation. This effect of olfactory deprivation on sexual behavior may be mediated by $\mathrm{GnRH}$ neurons. Indeed, as mentioned previously, GnRH cells receive olfactory information from both the main and the accessory olfactory system and an icv injection with $\mathrm{GnRH}$ is able to overcome the absence of olfactory inputs in a way similar to that of sexual experience [29,30,77,79]. Therefore, it is possible that sexual experience modulates the relative functional efficiency of these MOB to GnRH neuron connections; these connections gaining functional efficiency only after sexual experience. To support this hypothesis, it has been shown that, female chemosensory cues are better able to induce MPOA activation (a structure where GnRH neurons are located), measured through Fos immunocytochemistry, in sexually experienced than in naive males. This compensation between both olfactory systems may however not be a general rule as previously mentioned in male mice, where lesion of main olfactory epithelium disrupted mating behavior in sexually naïve [119] as well as sexually experienced animals [45], suggesting that vomeronasal inputs are not sufficient to sustain copulation in this species.

In the female, early studies $[28,108]$ also pointed to a role for the main olfactory system in the display of female sexual receptivity, since destruction of the MOE by intranasal infusion with zinc sulphate attenuated lordosis behavior in estrogen-progesteronetreated mice. In accordance with these results, recent experiments showed that destruction of the MOE reduced lordosis (in ovariectomized females primed with estradiol and progesterone) quotients by approximately $50 \%$ [45]. These results suggest that deprivation of main olfactory sensory input may induce less activation of the brain centers regulating lordosis and as a consequence impairs lordosis behavior. However, these effects of MOE lesions did not did not disrupt lordosis as effectively as did VNO lesions. Thus, VNO lesions completely abolished lordosis behavior in females of several mammalian species including hamsters [68], voles [22], rats [89] and mice [45]. Intriguingly, studies on the role of the VNO in the Bruce effect in mice showed that VNO ablation did not prevent female mice from becoming pregnant [50,64], suggesting that the VNO may not mediate female sexual receptivity in mice. However, both sets of data can be reconciled considering the time of exposure of the female to a stimulus male. Indeed, it is has been shown that the adverse effects of VNO lesions can be overcome by long-term exposure to the male. For example, the lordosis quotient of VNO-lesioned female rats increased after prolonged exposure to the male [89]. Whether females are sexually experienced or not prior to VNO removal may also play a role.

\section{Sexual differentiation of both olfactory systems}

Sexual behaviors displayed by males and females are clearly differentiated. As olfaction is the major sensory modality regulating sexual interactions, at least in rodents, it is not surprising that the olfactory systems show sexual dimorphisms at both morphological and functional levels. These sexual dimorphisms are the result of perinatal actions of gonadal hormones (see [4] or [73] for general principles regarding brain sexual differentiation). For example, the VNO, but also the whole vomeronasal system, is a sexually dimorphic chemosensory structure differentiated by gonadal hormones shortly after birth $[35,95-97,99]$. The overall volume, neuroepithelial volume, and number of bipolar neurons are all larger in male rats. These sex differences are abolished and inverted when males are gonadectomized and females are androgenized on the day of birth. Androgenized females had greater morphometric values than control females and in this regard resembled control males, while males castrated at birth did not differ from control females. Gonadal steroids maintained VNO structure in adulthood: when male and female rats were gonadectomized at 90 days and sacrificed at 180 days, a decrease in the VNO neuroepithelial height occurred in sexes [98]. Whether the same morphological sex differences exist in the main olfactory system is unknown.

Sex differences have also been reported in olfactory sensitivity at the functional level. For instance, sows are significantly better than boars at using decreasing concentrations of the volatile male pig pheromone, androstenone, to identify the presence of a food reward [25]. In addition, using positron emission tomography [92], women but not men showed a significant activation of the preoptic area and ventromedial nuclei of the hypothalamus when actively smelling androstadienone, an androgenic compound secreted by the axillary glands in higher concentrations in men than in women [34]. These sex differences in olfactory sensitivity are not only restricted to the detection of opposite-sex odors, but also involve samesex odors. For instance, using habituation/dishabituation tests to determine odor attraction thresholds, female mice respond more reliably than male mice to low concentrations of volatile urinary odors from either sex $[6,86]$. By contrast, other studies have shown that males were more proficient than females at discriminating between several types of urinary odors using an olfactometric device [112]. As with morphological differences, the existence of sex differences in olfactory sensitivity suggests that gonadal hormones may affect olfactory capabilities. These sex differences in olfactory sensitivity may reflect differences in circulating sex steroids at the time of testing (activational effects) or a hard-wired sex dimorphism in the functioning of the olfactory system that resulted from the perinatal actions of gonadal hormones (organizational effects). In this context, the aromatase knock-out (ArKO) mice have been used as a tool to assess the effects of perinatal estrogen exposure on social odor processing. ArKO females read- 
ily learned to discriminate urinary volatiles from ovariectomized females treated with estradiol as opposed to estradiol sequenced with progesterone and estradiol. Surprisingly, wild-type females failed to acquire this discrimination in a food-motivated go/no-go task [112]. Both wild-type and ArKO females successfully learned to discriminate between other types of volatile urinary odors, including those from gonadally intact male versus ovariectomized females primed with estradiol+ progesterone and those from gonadally intact versus castrated males. However, the different capacities of WT and ArKO females to discriminate volatile urinary odors from ovariectomized females treated with estradiol as opposed to oestradiol + progesterone cannot be explained by a difference between females of these two phenotypes in the ability of these two odors to activate distinguishable clusters of MOB glomeruli [70], suggesting that the central processing of social odors may be affected in female ArKO mice. In this respect, ArKO females that were treated with estradiol benzoate in adulthood to correct for their estrogen deficiency showed a normal, female-typical, Fos activation at the level of the olfactory bulbs when exposed to male urinary odors, but Fos responses were affected at more central levels [85]. Indeed, male odors still induced significant Fos expression in the medial amygdala of ArKO females, although this increase was clearly reduced in comparison with WT female mice, and failed to activate the VMH, a brain region critical for the expression of reproductive behavior in female mice. This result suggests that, in ArKO females, olfactory cues from a potential mate are correctly detected at the level of the olfactory bulb but that the integration of their reproductive value at the level of the amygdala and VMH is reduced, which may explain their deficits in the expression of sexual behavior [5]. Different patterns of Fos expression following exposure to urinary odors from conspecifics of both sexes were also observed in the amygdala of WT and ArKO males, a region that seems to be essential for the integration of olfactory stimuli in mice [20], suggesting that perinatal estrogens may be involved in the development of this brain area in both males and females. Finally, these results confirmed previously observed sex differences in neural activation of the accessory olfactory pathway following exposure to male odors [36], although no significant Fos responses were observed in central brain regions of male ArKO mice when exposed to male urine, suggesting that these sex differences probably reflect the perinatal actions of androgens as was recently suggested by the work of Bodo and Rissman [9].

\section{Conclusion}

We have reviewed the current view of how the mammalian main and accessory olfactory systems detect partially overlapping sets of social chemosensory cues, giving rise to a model that involves parallel processing of the same molecules but through different mechanisms leading to specific behavioral outputs. Consequently, both systems should be conceived as complementary rather than as separate pathways. Further experimentation will be needed to understand how chemosensory cues are integrated with hormonal and neuroendocrine factors to control courtship and mating behaviors.

\section{Acknowledgements}

Matthieu Keller is a CNRS research associate (France); Michael Baum is professor of Biology at Boston University (USA); Peter Brennan is reader at the University of Bristol (UK); Julie Bakker is a FNRS research associate (Belgium). The preparation of this manuscript was made possible through the support of the following grants: NICHD No. 044897 to JB and MJB; FNRS-Mandat d'Impulsion Scientifique to JB and INSERM, Programme National de Recherche en Reproduction et Endocrinologie grant to MK.

\section{References}

[1] Andreolini F, Jemiolo B, Novotny M. Dynamics of excretion of urinary chemosignals in the house mouse (Mus musculus) during the natural estrous cycle. Experientia 1987;43:998-1002.

[2] Aujard F. Effect of vomeronasal organ removal on male socio-sexual responses to female in a prosimian primate (Microcebus murinus). Physiol Behav 1997;62:1003-8.

[3] Bakker J. Sexual differentiation of the neuroendocrine mechanisms regulating mate recognition in mammals. J Neuroendocrinol 2003;15:615-21.

[4] Bakker J, Baum MJ. Role for estradiol in female-typical brain and behavioral sexual differentiation. Front Neuroendocrinol 2008;29:1-16.

[5] Bakker J, Honda S, Harada N, Balthazart J. The aromatase knock-out mouse provides new evidence that estradiol is required during development in the female for the expression of sociosexual behaviors in adulthood. J Neurosci 2002;22:9104-12

[6] Baum MJ, Keverne EB. Sex difference in attraction thresholds for volatile odors from male and estrous female mouse urine. Horm Behav 2002;41: 213-9.

[7] Baum MJ, Kelliher KR. Complementary roles of the main and accessory olfactory systems in mammalian mate recognition. Annu Rev Physiol 2009;71:141-60.

[8] Bellringer JF, Pratt HP, Keverne EB. Involvement of the vomeronasal organ and prolactin in pheromonal induction of delayed implantation in mice. J Reprod Fertil 1980;59:223-8.

[9] Bodo C, Rissman EF. Androgen receptor is essential for sexual differentiation of responses to olfactory cues in mice. Eur J Neurosci 2007;25:2182-90.

[10] Boehm U, Zou Z, Buck LB. Feedback loops link odor and pheromone signaling with reproduction. Cell 2005;123:683-95.

[11] Brechbuhl J, Klaey M, Broillet MC. Grueneberg ganglion cells mediate alarm pheromone detection in mice. Science 2008;321:1092-5.

[12] Brennan PA. The nose knows who's who: chemosensory individuality and mate recognition in mice. Horm Behav 2004;46:231-40.

[13] Brennan PA. Outstanding issues surrounding vomeronasal mechanismsof pregnancy block and individual recognition in mice. Behav. Brain Res 2009;200:287-94.

[14] Brennan PA, Keverne EB. Something in the air? New insights into mammalian pheromones. Curr Biol 2004;14:R81-9.

[15] Brennan PA, Zufall F. Pheromonal communication in vertebrates. Nature 2006;444:308-15.

[16] Brennan PA, Schellinck HM, Keverne EB. Patterns of expression of the immediate-early gene egr- 1 in the accessory olfactory bulb of female mice exposed to pheromonal constituents of male urine. Neuroscience 1999;90:1463-70.

[17] Briand L, Huet J, Perez V, Lenoir G, Nespoulous C, Boucher Y, et al. Odorant and pheromone binding by aphrodisin, a hamster aphrodisiac protein. FEBS Lett 2000;476:179-85.

[18] Bruce HM. An exteroceptive block to pregnancy in the mouse. Nature 1959; $184: 105$.

[19] Buck LB. The molecular architecture of odor and pheromone sensing in mammals. Cell 2000;100:611-8.

[20] Choi GB, Dong HW, Murphy AJ, Valenzuela DM, Yancopoulos GD, Swanson LW, et al. Lhx6 delineates a pathway mediating innate reproductive behaviors from the amygdala to the hypothalamus. Neuron 2005;46:647-60.

[21] Cohen-Tannoudji J, Lavenet C, Locatelli A, Tillet Y, Signoret JP. Noninvolvement of the accessory olfactory system in the LH response of anoestrous ewes to male odour. J Reprod Fertil 1989;86:135-44.

[22] Curtis JT, Liu Y, Wang Z. Lesions of the vomeronasal organ disrupt matinginduced pair bonding in female prairie voles (Microtus ochrogaster). Brain Res 2001;901:167-74.

[23] Del Punta K, Leinders-Zufall T, Rodriguez I, Jukam D, Wysocki CJ, Ogawa S, et al. Deficient pheromone responses in mice lacking a cluster of vomeronasal receptor genes. Nature 2002;419:70-4.

[24] Delgadillo JA, Gelez H, et al. The 'male effect' in sheep and goats-Revisiting the dogmas. Behav. Brain Res 2009;200:304-14.

[25] Dorries KM, Adkins-Regan E, Halpern BP. Olfactory sensitivity to the pheromone, androstenone, is sexually dimorphic in the pig. Physiol Behav 1995;57:255-9.

[26] Dorries KM, Adkins-Regan E, Halpern BP. Sensitivity and behavioral responses to the pheromone androstenone are not mediated by the vomeronasal organ in domestic pigs. Brain Behav Evol 1997;49:53-62.

[27] Drickamer LC, Hoover JE. Effects of urine from pregnant and lactating female house mice on sexual maturation of juvenile females. Dev Psychobiol 1979;12:545-51.

[28] Edwards DA, Burge KG. Olfactory control of the sexual behavior of male and female mice. Physiol Behav 1973;11:867-72.

[29] Fernandez-Fewell GD, Meredith M.c-Fos expression in vomeronasal pathways of mated or pheromone-stimulated male golden hamsters: contributions from vomeronasal sensory input and expression related to mating performance. J Neurosci 1994; 14:3643-54.

[30] Fernandez-Fewell GD, Meredith M. Facilitation of mating behavior in male hamsters by LHRH and AcLHRH5-10: interaction with the vomeronasal system. Physiol Behav 1995;57:213-21.

[31] Firestein S. How the olfactory system makes sense of scents. Nature 2001;413:211-8. 
[32] Gelez H, Fabre-Nys C. The "male effect" in sheep and goats: a review of the respective roles of the two olfactory systems. Horm Behav 2004;46:257-71.

[33] Gomez DM, Newman SW. Differential projections of the anterior and posterior regions of the medial amygdaloid nucleus in the Syrian hamster. J Comp Neurol 1992;317:195-218.

[34] Gower DB, Ruparelia BA. Olfaction in humans with special reference to odorous 16-androstenes: their occurrence, perception and possible social, psychological and sexual impact. J Endocrinol 1993;137:167-87.

[35] Guillamon A, Segovia S. Sex differences in the vomeronasal system. Brain Res Bull 1997;44:377-82.

[36] Halem HA, Cherry JA, Baum MJ. Vomeronasal neuroepithelium and forebrain Fos responses to male pheromones in male and female mice. J Neurobiol 1999;39:249-63.

[37] Halem HA, Baum MJ, Cherry JA. Sex difference and steroid modulation of pheromone-induced immediate early genes in the two zones of the mouse accessory olfactory system. J Neurosci 2001;21:2474-80.

[38] Halpern M, Martinez-Marcos A. Structure and function of the vomeronasal system: an update. Prog Neurobiol 2003;70:245-318.

[39] Hudson R, Distel H. Pheromonal release of suckling in rabbits does not depend on the vomeronasal organ. Physiol Behav 1986;37:123-8.

[40] Hurst JL, Payne CE, Nevison CM, Marie AD, Humphries RE, Robertson DH, et al. Individual recognition in mice mediated by major urinary proteins. Nature 2001;414:631-4.

[41] Jakupovic J, Kang N, Baum MJ. Effect of bilateral accessory olfactory bulb lesions on volatile urinary odor discrimination and investigation as well as mating behavior in male mice. Physiol Behav 2008;93:467-73.

[42] Jemiolo B, Andreolini F, Xie TM, Wiesler D, Novotny M. Puberty-affecting synthetic analogs of urinary chemosignals in the house mouse, Mus domesticus. Physiol Behav 1989;46:293-8.

[43] Karlson P, Luscher M. Pheromones': a new term for a class of biologically active substances. Nature 1959;183:55-6.

[44] Keller M, Douhard Q, Baum MJ, Bakker J. Destruction of the main olfactory epithelium reduces female sexual behavior and olfactory investigation in female mice. Chem Senses 2006;31:315-23.

[45] Keller M, Douhard Q, Baum MJ, Bakker J. Sexual experience does not compensate for the disruptive effects of zinc sulfate-lesioning of the main olfactory epithelium on sexual behavior in male mice. Chem Senses 2006;31: 753-62.

[46] Keller M, Pierman S, Douhard Q, Baum MJ, Bakker J. The vomeronasal organ is required for the expression of lordosis behaviour, but not sex discrimination in female mice. Eur J Neurosci 2006;23:521-30.

[47] Keller M, Baum M], Bakker, J. Olfactory control of sex-recognition and sexual behavior in mice. In: Hurst JL, Beynon RJ, Roberts SC, Wyatt TD, editors. Chemical signals in vertebrates XI. Springer-Verlag, New York, 2008, ISBN 978-0-387-73944-1 2008241-50.

[48] Kelliher KR. The combined role of the main olfactory and vomeronasal systems in social communication in mammals. Horm Behav 2007:52:561-70.

[49] Kelliher KR, Baum MJ. Nares occlusion eliminates heterosexual partner selection without disrupting coitus in ferrets of both sexes. J Neurosci 2001;21:5832-40.

[50] Kelliher KR, Spehr M, Li XH, Zufall F, Leinders-Zufall T. Pheromonal recognition memory induced by TRPC2-independent vomeronasal sensing. Eur J Neurosci 2006;23:3385-90

[51] Keverne EB. The vomeronasal organ. Science 1999;286:716-20.

[52] Keverne EB. Importance of olfactory and vomeronasal systems for male sexual function. Physiol Behav 2004;83:177-87.

[53] Kevetter GA, Winans SS. Connections of the corticomedial amygdala in the golden hamster. II. Efferents of the "olfactory amygdala". J Comp Neurol 1981;197:99-111.

[54] Kevetter GA, Winans SS. Connections of the corticomedial amygdala in the golden hamster. I. Efferents of the "vomeronasal amygdala". J Comp Neurol 1981;197:81-98.

[55] Kimchi T, Xu J, Dulac C. A functional circuit underlying male sexual behaviour in the female mouse brain. Nature 2007;448:1009-14.

[56] Leinders-Zufall T, Lane AP, Puche AC, Ma W, Novotny MV, Shipley MT, et al. Ultrasensitive pheromone detection by mammalian vomeronasal neurons. Nature 2000;405:792-6.

[57] Leinders-Zufall T, Brennan P, Widmayer P, Chandramani SP, Maul-Pavicic A, Jäger $M$, et al. MHC class I peptides as chemosensory signals in the vomeronasal organ. Science 2004;306:1033-7.

[58] Levy F, Keller M, Poindron P. Olfactory regulation of maternal behavior in mammals. Horm Behav 2004;46:284-302.

[59] Lévy F, Keller M. Olfactory mediation of maternal behavior in selected mammalian species. Behav. Brain Res 2009;200:336-45

[60] Leypold BG, Yu CR, Leinders-Zufall T, Kim MM, Zufall F, Axel R. Altered sexual and social behaviors in trp2 mutant mice. Proc Natl Acad Sci USA 2002;99:6376-81.

[61] Licht G, Meredith M. Convergence of main and accessory olfactory pathways onto single neurons in the hamster amygdala. Exp Brain Res 1987;69:7-18.

[62] Lin DY, Zhang SZ, Block E, Katz LC. Encoding social signals in the mouse main olfactory bulb. Nature 2005;434:470-7.

[63] Lin W, Arellano J, Slotnick B, Restrepo D. Odors detected by mice deficient in cyclic nucleotide-gated channel subunit A2 stimulate the main olfactory system. J Neurosci 2004;24:3703-10.

[64] Lloyd-Thomas A, Keverne EB. Role of the brain and accessory olfactory system in the block to pregnancy in mice. Neuroscience 1982;7:907-13.
[65] Lomas DE, Keverne EB. Role of the vomeronasal organ and prolactin in the acceleration of puberty in female mice. J Reprod Fertil 1982;66:101-7.

[66] Luo M, Fee MS, Katz LC. Encoding pheromonal signals in the accessory olfactory bulb of behaving mice. Science 2003;299:1196-201.

[67] Ma D, Allen ND, Van Bergen YC, Jones CM, Baum MJ, Keverne EB, et al. Selective ablation of olfactory receptor neurons without functional impairment of vomeronasal receptor neurons in OMP-ntr transgenic mice. Eur J Neurosci 2002;16:2317-23.

[68] Mackay-Sim A, Rose JD. Removal of the vomeronasal organ impairs lordosis in female hamsters: effect is reversed by luteinising hormone-releasing hormone. Neuroendocrinology 1986;42:489-93.

[69] Mandiyan VS, Coats JK, Shah NM. Deficits in sexual and aggressive behaviors in Cnga2 mutant mice. Nat Neurosci 2005;8:1660-2.

[70] Martel KL, Keller M, Douhard Q Bakker J, Baum MJ. Comparison of odorinduced glomerular activation in the main olfactory bulb of aromatase knock-out and wild type female mice. Neurosci Lett 2007;421:102-7.

[71] Martel KL, Baum MJ. A centrifugal pathway to the mouse accessory olfactory bulb from the medial amygdala conveys gender-specific volatile pheromonal signals. Eur J Neurosci 2009;29(2):368-76.

[72] Martinez-Ricos J, Agustin-Pavon C, Lanuza E, Martinez-Garcia F. Role of the vomeronasal system in intersexual attraction in female mice. Neuroscience 2008;153:383-95.

[73] McCarthy MM. Estradiol and the developing brain. Physiol Rev 2008;88: 91-124.

[74] Meredith M. Vomeronasal organ removal before sexual experience impairs male hamster mating behavior. Physiol Behav 1986;36:737-43.

[75] Meredith M. Sensory processing in the main and accessory olfactory systems: comparisons and contrasts. J Steroid Biochem Mol Biol 1991;39:601-14.

[76] Meredith M. Chronic recording of vomeronasal pump activation in awake behaving hamsters. Physiol Behav 1994;56:345-54.

[77] Meredith M. Vomeronasal, olfactory, hormonal convergence in the brain. Cooperation or coincidence? Ann N Y Acad Sci 1998;855:349-61.

[78] Meredith M, O'Connell RJ. Efferent control of stimulus access to the hamster vomeronasal organ. J Physiol 1979;286:301-16.

[79] Meredith M, Howard G. Intracerebroventricular LHRH relieves behavioral deficits due to vomeronasal organ removal. Brain Res Bull 1992;29: 75-9.

[80] Meredith M, Fewell G. Vomeronasal organ: electrical stimulation activates Fos in mating pathways and in GnRH neurons. Brain Res 2001;922:87-94.

[81] Novotny M, Harvey S, Jemiolo B, Alberts J. Synthetic pheromones that promote inter-male aggression in mice. Proc Natl Acad Sci USA 1985;82: 2059-61.

[82] Pankevich DE, Baum MJ, Cherry JA. Olfactory sex discrimination persists, whereas the preference for urinary odorants from estrous females disappears in male mice after vomeronasal organ removal. J Neurosci 2004;24: 9451-7.

[83] Pankevich DE, Cherry JA, Baum MJ. Effect of vomeronasal organ removal from male mice on their preference for and neural Fos responses to female urinary odors. Behav Neurosci 2006;120:925-36.

[84] Pfeiffer CA, Johnston RE. Hormonal and behavioral responses of male hamsters to females and female odors: roles of olfaction, the vomeronasal system, and sexual experience. Physiol Behav 1994;55:129-38.

[85] Pierman S, Douhard Q Bakker J. Evidence for a role of early oestrogens in the central processing of sexually relevant olfactory cues in female mice. Eur J Neurosci 2008;27:423-31.

[86] Pierman S, Douhard Q, Balthazart J, Baum MJ, Bakker J. Attraction thresholds and sex discrimination of urinary odorants in male and female aromatase knockout (ArKO) mice. Horm Behav 2006;49:96-104.

[87] Powers JB, Winans SS. Vomeronasal organ: critical role in mediating sexual behavior of the male hamster. Science 1975;187:961-3.

[88] Preti G, Wysocki CJ, Barnhart KT, Sondheimer SJ, Leyden JJ. Male axillary extracts contain pheromones that affect pulsatile secretion of luteinizing hormone and mood in women recipients. Biol Reprod 2003;68:2107-13.

[89] Rajendren G, Dudley CA, Moss RL. Role of the vomeronasal organ in the male-induced enhancement of sexual receptivity in female rats. Neuroendocrinology 1990;52:368-72.

[90] Restrepo D, Arellano J, Oliva AM, Schaefer ML, Lin W. Emerging views on the distinct but related roles of the main and accessory olfactory systems in responsiveness to chemosensory signals in mice. Horm Behav 2004;46:247-56.

[91] Rodriguez I. Pheromone receptors in mammals. Horm Behav 2004;46:219-30.

[92] Savic I, Berglund H, Gulyas B, Roland P. Smelling of odorous sex hormone-like compounds causes sex-differentiated hypothalamic activations in humans. Neuron 2001;31:661-8.

[93] Scalia F, Winans SS. The differential projections of the olfactory bulb and accessory olfactory bulb in mammals. J Comp Neurol 1975;161:31-55.

[94] Schaal B, Coureaud G, Langlois D, Ginies C, Semon E, Perrier G. Chemical and behavioural characterization of the rabbit mammary pheromone. Nature 2003;424:68-72.

[95] Segovia S, Guillamon A. Effects of sex steroids on the development of the vomeronasal organ in the rat. Brain Res 1982;281:209-12.

[96] Segovia S, Guillamon A. Sexual dimorphism in the vomeronasal pathway and sex differences in reproductive behaviors. Brain Res Brain Res Rev 1993;18:51-74.

[97] Segovia S, Guillamon A. Searching for sex differences in the vomeronasal pathway. Horm Behav 1996;30:618-26. 
[98] Segovia S, Paniagua R, Nistal M, Guillamon A. Effects of postpuberal gonadectomy on the neurosensorial epithelium of the vomeronasal organ in the rat Brain Res 1984;316:289-91.

[99] Segovia S, Guillamon A, del Cerro MC, Ortega E, Perez-Laso C, Rodriguez-Zafra $\mathrm{M}$, et al. The development of brain sex differences: a multisignaling process. Behav Brain Res 1999;105:69-80.

[100] Shinohara K, Morofushi M, Funabashi T, Kimura F. Axillary pheromones modulate pulsatile LH secretion in humans. Neuroreport 2001;12:893-5.

[101] Sorwell KG, Wesson DW, Baum MJ. Sexually dimorphic enhancement by estradiol of male urinary odor detection thresholds in mice. Behav Neurosci 2008;122:788-93.

[102] Spehr M, Spehr J, Ukhanov K, Kelliher KR, Leinders-Zufall T, Zufall F. Parallel processing of social signals by the mammalian main and accessory olfactory systems. Cell Mol Life Sci 2006;63:1476-84.

[103] Spehr M, Kelliher KR, Li XH, Boehm T, Leinders-Zufall T, Zufall F. Essential role of the main olfactory system in social recognition of major histocompatibility complex peptide ligands. J Neurosci 2006;26:1961-70.

[104] Stern K, McClintock MK. Regulation of ovulation by human pheromones. Nature 1998;392:177-9.

[105] Stowers L, Holy TE, Meister M, Dulac C, Koentges G. Loss of sex discrimination and male-male aggression in mice deficient for TRP2. Science 2002;295:1493-500.

[106] Swaney WT, Keverne EB. The evolution of pheromonal communication. Behav Brain Res 2009;200:239-47.

[107] Swanson LW, Petrovich GD. What is the amygdala? Trends Neurosc 1998;21:323-31.

[108] Thompson ML, Edwards DA. Olfactory bulb ablation and hormonally induced mating in spayed female mice. Physiol Behav 1972;8:1141-6.

[109] Trinh K, Storm DR. Vomeronasal organ detects odorants in absence of signaling through main olfactory epithelium. Nat Neurosci 2003;6:519-25.
[110] Vandenbergh JG. Male odor accelerates female sexual maturation in mice. Endocrinology 1969;84:658-60.

[111] von Campenhausen H, Mori K. Convergence of segregated pheromonal pathways from the accessory olfactory bulb to the cortex in the mouse. Eur J Neurosci 2000;12:33-46.

[112] Wesson DW, Keller M, Douhard Q, Baum MJ, Bakker J. Enhanced urinary odor discrimination in female aromatase knockout (ArKO) mice. Horm Behav 2006;49:580-6

[113] Westberry J, Meredith M. The influence of chemosensory input and gonadotropin releasing hormone on mating behavior circuits in male hamsters. Brain Res 2003;974:1-16.

[114] Westberry JM, Meredith M. Pre-exposure to female chemosignals or intracerebral GnRH restores mating behavior in naive male hamsters with vomeronasa organ lesions. Chem Senses 2003;28:191-6.

[115] Whitten WK. Physiological control of population growth. Nature 1956;178:992.

[116] Woodley SK, Cloe AL, Waters P, Baum MJ. Effects of vomeronasal organ removal on olfactory sex discrimination and odor preferences of female ferrets. Chem Senses 2004;29:659-69.

[117] Wysocki CJ, Yamazaki K, Curran M, Wysocki LM, Beauchamp GK. Mice (Mus musculus) lacking a vomeronasal organ can discriminate MHC-determined odortypes. Horm Behav 2004;46:241-6.

[118] Xu F, Schaefer M, Kida I, Schafer J, Liu N, Rothman DL, et al. Simultaneous activation of mouse main and accessory olfactory bulbs by odors or pheromones. J Comp Neurol 2005;489:491-500.

[119] Yoon H, Enquist LW, Dulac C. Olfactory inputs to hypothalamic neurons controlling reproduction and fertility. Cell 2005;123:669-82.

[120] Zufall F, Leinders-Zufall T. Mammalian pheromone sensing. Curr Opin Neurobiol 2007;17:483-9. 